\title{
A DESCRIPTION AND COMPARISON OF THE LEVELS OF ANXIETY AMONG COLLEGE ADMINISTRATORS
}

\author{
Mehmet Durdu Karsli and Mustafa BaloĞLU \\ Gaziosmanpasa University, Tokat, Turkey
}

\begin{abstract}
Administrators, in general, are at greater risk of facing anxiety than are other people, due to their duties and responsibilities. In this study, both state and trait anxiety levels of college administrators were assessed and the administrators were compared based on their anxiety levels. For the purpose of assessing state and trait anxiety levels, the State-Trait Anxiety Inventory (STAI) (Spielberger, Gorsuch, \& Lushene, 1970) adapted to Turkish by LeCompte and Oner (1975) was used. The sample of the study included 72 college administrators who were working in Turkish state and private universities in different regions of the country. Results showed significant correlation between the state and trait anxiety levels. No significant difference was found based on gender, age, administrative level, or tenure. However, the direction of the differences was similar to those of the previous studies. Results are discussed and suggestions are given.
\end{abstract}

Keywords: college administrators, state anxiety, trait anxiety, Turkey.

Although anxiety is difficult to define and measure (Lang, 1968), it is one of the most studied constructs in the fields of psychology (McReynolds, 1972). In general, anxiety is defined as "a complex reaction that is a transitory condition of the organism that varies in intensity and fluctuates over time" (Strawderman, 1985, p. 21). Schwarzer, Van der Ploeg, and Spielberger (1982) held that anxiety is an unpleasant emotional reaction that results from perception or appraisal of a particular situation as threatening. Spielberger (1972) defined anxiety as "a

Mehmet Durdu Karsli, PhD, and Mustafa Baloğlu, PhD, Department of Educational Sciences, College of Education, Gaziosmanpasa University, Tokat, Turkey.

Appreciation is due to reviewers including: Bernadette Gadzella, $\mathrm{PhD}$, Department of Psychology and Special Education, Texas A \& M University, Commerce, TX 75429, USA. Email: BernadetteGadzella@tamu-commerce.edu

Please address correspondence and reprint requests to: Dr. Mehmet Durdu Karsli, Gaziosmanpasa University, College of Education, Department of Educational Sciences, Taslicoftlik Campus 60240, Tokat, Turkey. Phone: +90 356 2521629; Fax: +90 356252 1625; Email: mkarsli@gop.edu.tr; mkarsl@yahoo.com; mkdurdu@hotmail.com 
palpable but transitory emotional state or condition characterized by feelings of tension and apprehension and heightened autonomic nervous activity" (p. 24). Most of these definitions seem to accentuate a particular aspect of anxiety. That is, they regard anxiety as a response to an external threat.

In general, administration can be defined as an art of helping others do their jobs (Inci, 1986). The main aim of administration is to motivate people around common goals and direct them in reaching those goals. In other words, administration is gaining workers' cooperation in working towards agreed-upon common goals (Schermerhorn, 1983). There are a total of 71 universities in Turkey of which 17 are private universities. These universities, composed of tens of departments and serving the common needs of thousands of people, are at the top of the organizations that are in need of effective and efficient administrators. In general, administrators are at greater risk of facing anxiety than are other people, owing to their duties and responsibilities (Pehlivan, 1995). In addition, university administrators' risk of facing anxiety is increased because of their greater social and economic responsibilities. The nature of their jobs, work environment, relationships with their superiors, friends, or students are only some of many factors that might cause anxiety among college administrators (Ikizler, 1994). Moreover, these people have special anxiety sources springing from their positions. Some of these sources are decision making, being involved in certain decisions, the lack of authority, the uneasiness of having responsibilities, inconsistencies in evaluations, the lack of encouragement, time pressure, the lack of financial resources, and so on. All the sources of anxiety that have been listed are mainly the result of working in a college environment. Therefore, they are specifically related to certain types of environments. That is why this type is called state anxiety in the literature (Spielberger, 1972). Another type of anxiety is more like a personality trait, a more persistent type which is called trait anxiety (Spielberger, 1972). In the present study, both state and trait anxiety levels of college administrators were assessed and compared on several characteristics such as age, gender, position, and tenure.

\section{METHOD}

\section{SAMPLE}

Participants in this study were 72 college administrators who were working in universities in Turkey. In the group, there were 55 (76.4\%) men and 17 (23.6\%) women. Participants' ages ranged from 27 to 63 years with a mean of $45.60(S D=7.70)$ and median of 45 years. Most participants were married $(91.7 \%)$ and working in a state university $(94.4 \%)$. The range of working years as an administrator was from one to 28 years $(M=7.32, S D=7.04)$. When the administrative levels of the participants were examined, 28 were in middle level 
administrative positions such as head of program (38.9\%), 20 were in middle level administrative positions such as department chair (27.8\%), and 17 were in upper level administrative positions such as dean of college (23.6\%). Seven participants (9.7\%) did not respond to this question. Participants were asked whether they had willingly chosen their careers in administration. Sixty-nine (95.8\%) responded in the affirmative to this question. The administrators in this study were working, on average, 47.91 hours a week $(S D=16.43)$. Most administrators indicated that they fulfilled their expectations in their administrative careers $(69.4 \%)$, whereas about one-fifth (19.4\%) indicated that they did not fulfill their expectations. Seven administrators did not know whether they fulfilled their expectations or not, and one administrator did not respond to this question. Finally, when they were asked about their effectiveness in their jobs, $4(5.6 \%)$ did not have any idea; $8(11.1 \%)$ perceived themselves as "not bad" 43 (59.7\%) found themselves "effective" and 17 (23.6\%) "quite effective".

\section{INSTRUMENT}

The Turkish form of the State Trait Anxiety Inventory (STAI) and a demographic questionnaire were used to collect data in this study. The STAI, a 40-item, 4point Likert-type instrument, was developed to measure transitory emotional and relatively stable anxiety reactions (Spielberger, Gorsuch, \& Lushene, 1970). The first items in the inventory measure feelings of apprehension, tension, nervousness, and worry about the current situation (A-State) and the last 20 items assess how the respondents feel in general (A-Trait).

The validity and the reliability of the STAI have been extensively studied in the literature. Spielberger et al. (1970) found that A-State anxiety scores were significantly higher in the examination condition than in the normal condition. Coefficient alpha reliability of the A-State was found to be .91 for men and .93 for women; and A-Trait was found to be .90 for men and .91 for women (Spielberger, 1983). The test-retest reliability studies proved that A-Trait anxiety was relatively stable over time. Spielberger et al. found satisfactory test-retest reliability evidence (.65 to .86) for intervals up to 3 months. Spielberger (1980) also reported that A-Trait scores of 197 university students had .84 (men) and .76 (women) one-hour test-retest reliability. A 20-day test-retest reliability was found to be .86 and .76 for men and women, respectively.

The STAI was translated and adapted to Turkish (LeCompte \& Oner, 1975) and the Turkish form was found to be reliable and valid (LeCompte \& Oner, 1975; Oner \& LeCompte, 1983). In the present study, internal consistency and Spearman-Brown split-half reliability of the A-State scale were found to be .92. In terms of the A-Trait scale, internal consistency was found to be .80 and Spearman-Brown split-half reliability was found to be .82 . 


\section{Procedure}

University administrators were asked whether they would want to participate in the study after a brief explanation about its nature had been given. Those who were willing to participate responded to a brief demographic questionnaire and the Turkish form of the STAI. In order to ensure confidentiality, participants were asked to write no identifying information on the packets. Upon completion, the packets were collected and the participants were debriefed. Debriefing included a statement of appreciation for participation and a brief description of the study. Data were screened for accuracy and for the assumptions of parametric statistics. Normality, homogeneity of variance, and linearity assumptions were tested at univariate, bivariate, and multivariate levels.

\section{RESULTS}

In this study, college administrators' state anxiety levels ranged from 20 to 49 with a mean of $32.60(S D=8.25)$ and median of 31.00. Trait anxiety levels ranged from 23 to $56(M=39.54, S D=6.69, M d n=40.00)$. The relationship between the state and trait anxiety levels was statistically significant $(r=.81, p$ $<.0005)$.

A comparison was made to test whether gender made a significant difference on the state or trait anxiety levels. In terms of state anxiety, even though male administrators $(M=33.04, S D=8.58)$ scored higher than female administrators $(M=31.18, S D=7.09)$, the difference was not statistically significant $\left(t_{(70)}=\right.$ $.81, p<.42)$. In terms of trait anxiety, male $(M=39.55, S D=6.95)$ and female $(M=39.53, S D=5.94)$ administrators scored very close $(p<.42)$. The age variable was split into two categories to compare younger (age $<45$ years) and older (age >45) administrators' anxiety levels. In terms of state anxiety, younger administrators $(M=34.19, S D=7.81)$ showed higher levels of anxiety than did older $(M=30.91, S D=8.47)$ administrators $\left(t_{(70)}=1.71, p<.09\right)$. In the same way, younger administrators $(M=40.54, S D=5.34)$ showed higher levels of trait anxiety than did older administrators $(M=38.49, S D=7.81)$, but the difference was not statistically significant $\left(t_{(70)}=1.31, p<.20\right)$.

One-way ANOVA was performed to test whether there was a significant difference on the anxiety levels depending upon the administrative level. As Table 1 shows, there was no significant difference among the groups.

Finally, the number of working years as an administrator and anxiety levels were compared. Those who had been working as administrators for less than 10 years were compared to those who had been working more than 10 years. Even though those who had been working as administrators for less than 10 years ( $M$ $=33.06, S D=7.55$ and $M=40.04, S D=5.33$ ) scored higher than did those who had been working more than 10 years $(M=31.72, S D=9.52$ and $M=38.60, S D$ 
$=8.75)$ both on state and trait anxiety levels, the differences were not significant $t_{(70)}=.66, p<.51$ and $\left.t_{(70)}=.87, p<.39\right)$.

TABLE 1

AnXiety Differences among Different Administrative LeVels

\begin{tabular}{lcccccrr}
\hline & \multicolumn{2}{c}{ Middle Level } & \multicolumn{3}{c}{ Mid-upper Level } & \multicolumn{2}{c}{ Upper Level } \\
\cline { 2 - 8 } & $M$ & $S D$ & $M$ & $S D$ & $M$ & $S D$ & $F^{*}$ \\
\hline State Anxiety & 32.89 & 6.48 & 30.60 & 7.78 & 33.06 & 11.13 & .56 \\
Trait Anxiety & 40.21 & 5.04 & 37.00 & 5.37 & 39.24 & 9.24 & 1.43 \\
\hline
\end{tabular}

* none significant

\section{DISCUSSION}

Getting stressed out at work is something everybody experiences. However, there is a difference between being stressed out by your job and having high levels of anxiety. The results of this study show that college administrators display higher levels of anxiety than do other workers. There is also a significant relationship between college administrators' state anxiety and trait anxiety levels. This finding indicates that the levels of anxiety among college administrators do not fluctuate easily but rather they remain stable over time. College administrators are always anxious. We believe that this anxiety comes partly as a result of the greater responsibilities that the administrators carry on their jobs. It can also be inferred that these administrators try to protect their positions and face anxiety. As the literature indicates that there is a negative relationship between anxiety and performance (Tobias, 1986; Wine, 1980). There is a greater possibility of some sort of reduction in the efficiency of the administrators owing to the higher levels of anxiety they experience.

Results also show that there was no significant difference according to gender among the administrators, even though male administrators had higher anxiety levels compared to the female administrators. Thus, the results indicate that female administrators can be as comfortable as male administrators in managing large organizations such as universities. Currently, there are more male than female administrators at all levels of administration in Turkey, and universities are no exception. This result might become an encouragement for females who are planning to take administrative positions at universities.

Even though there was no significant difference on anxiety levels between younger and older administrators, younger administrators tend to show higher levels of anxiety than do the older ones. Being newer to the working conditions of the position might be the reason for this slight increase in anxiety levels. Literature indicates that cognitive dissonance arouses anxiety, and anxiety is 
triggered by situations that involve change in environment (Tobias, 1986). The result might be interpreted as showing that younger administrators are more motivated to keep their administrative positions and, because of these high levels of motivation, anxiety is aroused. In addition, the higher working loads might be pushing the intellectual and/or physical capacities of the administrators and thus causing the anxiety. Results show that tenure does not have much effect on anxiety. This shows a misperception regarding the role of experience in the administration of colleges. Our results show that younger and older administrators do not differ, at least on anxiety. Inconsistencies regarding the distribution of responsibilities in organizational structure, frequent changes in the governing regulations, and financial instabilities in Turkish universities might be affecting the younger administrators more than their older counterparts.

As a result, the higher levels of anxiety in university administrators might cause negative effects in both their physical health and effectiveness. Administrators who experience higher levels of anxiety should seek appropriate solutions and learn to cope effectively with anxiety.

Last but not least, this study was conducted on a limited number of administrators. Therefore, similar studies with higher numbers of participants are needed. Also needed are comparative studies between administrators who work in universities and those who work in other educational settings such as primary/secondary schools, vocational schools etc.

\section{REFERENCES}

Ikizler, C. (1994). Sporda başarının psikolojisi (The psychology of success in sports). Istanbul: Alfa Press.

Inci, A. (1986). The sources of organization stress: An application on managers. Istanbul: Basisen Culture and Education Series.

Lang, P. J. (1968). Fear reducation and fear behavior: Problems in treating a construct. In J. M. Shlien (Ed.), Research in psychotherapy: Vol. 3. Washington, DC: American Psychological Association.

McReynolds, P. A. (1972). The measurement of anxiety. In S. B. Sells \& R. G. Demaree (Eds.), Needed research on stress and anxiety: A special report of the USOE-sponsored grand study: Critical appraisal of research in the personality-emotions-motivation domain. IBR Report No: 72-10.

Oner, N., \& LeCompte, W. A. (1983). Durumluk-Surekli kaygi Envanteri el kitabi (The State-Trait Anxiety Inventory manual). Istanbul: Bogazici University Publications.

Pehlivan, I. (1995). Yönetimde stres kaynakları (Sources of stress in administration). Ankara: Pegem Publication.

Schermerhorn, R. J. (1983). Management for productivity. New York: John Wiley \& Sons Inc.

Schwarzer, R., Van der Ploeg, H. M., \& Spielberger, C. D. (1982). Test anxiety: An overview of theory and research (pp. 3-9). In R. Schwarzer, H. M. Van der Ploeg, \& C. D. Spielberger (Eds). (1982). Hillsdale, NJ: Lawrence Erlbaum Associates Inc.

Spielberger, C. D. (1972). Current trends in theory and research in anxiety. In C. D. Spielberger (Ed.), Anxiety: Current trends in theory and research (pp. 2-33). New York: Academic Press. 
Spielberger, C. D. (1980). Preliminary professional manual for the Test Anxiety Inventory. Palo Alto, CA: Consulting Psychologists Press.

Spielberger, C. D. (1983). Manual for the State-Trait Anxiety Inventory. Palo Alto, CA: Consulting Psychologists Press.

Spielberger, C. D., Gorsuch, R. L., \& Lushene, R. E. (1970). Manual for the State-Trait Anxiety Inventory. Palo Alto, California: Consulting Psychologists Press.

Strawderman, V. W. (1985). A description of mathematics anxiety using an integrative model. Unpublished doctoral dissertation, Georgia State University.

Tobias, S. (1986). Anxiety and cognitive processing of instruction. In R. Schwarzer (Ed.). Selfrelated cognitions in anxiety and motivation. Hillsdale, NJ: Lawrence Erlbaum Associates.

Wine, J. (1980). Cognitive-attentional theory of test anxiety. In I. G. Sarason (Ed.). Test anxiety: Theory, research and applications. Hillsdale, NJ: Lawrence Erlbaum Associates. 
